Jurnal Psikologi Malahayati, Volume 2, No.2, September 2020: 48-56

\title{
PELATIHAN OUTBOUND UNTUK MENINGKATKAN SELF EFFICACY PADA SISWA SMK
}

\author{
Syarifah Ivonesti ${ }^{1}$, Rany Fitriany ${ }^{2}$, Laily Maghviroh ${ }^{3}$
}

1Program Studi Pendidikan Anak Usia Dini, STAIN Bengkalis, email : ivonestis@yahoo.co.id 2Fakultas Psikologi, Universitas Putra Indonesia "YPTK" Padang, email : ranyfitriany@yahoo.com ${ }^{3}$ Fakultas Psikologi, UIN Sultan Syarif Kasim Riau

\section{ABSTRACT: OUTBOND TRAINING TO INCREASE SELF EFFICACY IN VOCATIONAL SCHOOL STUDENT}

This study aims to see the effect of outbound training in increasing self-efficacy of vocational students. Data collection using a self-efficacy scale, interviews and observations. The research design used was The one Group Pretest-postest Design. The analysis used two related sample tests with the Wilcoxon test and qualitative analysis to describe the effect of outbound training to increase self-efficacy in vocational students. The results showed that there was an effect of outbound training on the self-efficacy of vocational students. The influence is positive, which means that when vocational students receive outbound training, the self-efficacy of vocational students will get positive changes related to self-efficacy.

\section{Keywords: Outbond Training, Self efficacy, Vocational Students}

Penelitian ini bertujuan untuk melihat pengaruh pelatihan outbound dalam meningkatkan self efficacy siswa SMK. Pengumpulan data menggunakan skala self efficacy, wawancara dan observasi. Desain penelitian yang digunakan adalah The one Group Pretest-postest Design. Analisis menggunakan two related sample test dengan uji Wilcoxon dan analisis kualitatif untuk mendeskripsikan pengaruh pelatihan outbound untuk meningkatkan self efficacy pada siswa SMK. Hasil penelitian menunjukkan bahwa ada pengaruh pelatihan outbound terhadap self efficacy siswa SMK. Adapun bentuk pengaruhnya adalah positif, yang artinya ketika siswa SMK mendapatkan pelatihan outbound maka self efficacy siswa SMK akan mendapatkan perubahan yang positif terkait self efficacynya.

\section{Kata kunci: Pelatihan Oubound, Self Efficacy, Siswa SMK}

\section{PENDAHULUAN}

Sekolah merupakan organisasi yang memiliki tujuan untuk mewujudkan pembangunan nasional. Pembangunan nasional dapat tercapai dengan lahirnya generasi muda yang cerdas dan berahklak mulia. Sekolah merupakan tempat belajar, bekarya, dan berlatih mengembangkan skill sehingga mampu bersaing dan mampu untuk memasuki dunia kerja.

Salah satu lembaga pendidikan yang memiliki tujuan untuk menyiapkan siswanya agar langsung mampu dan siap memasuki dunia kerja adalah SMK. SMK memiliki tujuan pendidikan berdasarkan Depdiknas, (2006) yaitu mampu mewujudkan karir masa depan yang sesuai dengan kebutuhan, mengidentifikasi sumber - sumber dunia kerja, mengidentifikasi peluang-peluang pekerjaan masa ini dan masa datang, dan meneliti peluang pekerjaan. Melihat dari tujuan jenjang Pendidikan SMK yang utama adalah siswa SMK yang di harapkan mampu untuk mewujudkan karir masa depan atau masa akan datang atau pekerjaan bahkan pasiion yang sesuai dengan kebutuhan dunia kerja.

SMK merupakan salah satu Lembaga Pendidikan yang memiliki karakteristik berbeda dari sekolah umum yaitu terdapat mata pelajaran praktik. 
Jurnal Psikologi Malahayati, Volume 2, No.2, September 2020: 48-56

\section{PELATIHAN OUTBOND UNTUK MENINGKATKAN SELF EFFICACY PADA SISWA SMK}

Mata pelajaran praktik yang memiliki fungsi membekali peserta didik agar memiliki kompetensi kerja sesuai dengan standar Kompetensi Kerja Nasional Indonesia (SKKNI) atau standar kompetensi yang disepakati oleh lembaga yang mewakili dunia usaha atau industri. Pelajaran Praktik di ajarkan secara spesifik sesuai dengan kebutuhan tiap program keahlian. Pelajaran produktif (praktik) mempunyai jumlai jam yang banyak dibandingkan dengan jumlah jam pelajaran dengan jumlah jam pelajaran normatif atau adaptif (GBPP, 2004). Menurut Syahni (Widyasari, 2015) pembelajaran di SMK sebesar $70 \%$ diisi dengan praktik dan hanya $30 \%$ teori, dikarenakan lulusan SMK dituntut memiliki keahlian tertentu.

Jadwal belajar di SMK lebih banyak mengutamakan praktik kerja dan teori - teori yang di butuhkan siswa untuk mempersiapkan memasuki di dunia kerja yang disesuaikan dengan jurusan. Selain itu, tugas - tugas yang besifat skill berupa praktek kerja langsung jumlah waktu belajar lebih banyak dan juga menyarankan agar siswa SMK untuk aktif mengikuti kegiatan organisasi. Melalui kegiatan belajar dan kegiatan organisasi diharapkan mengahasilkan siswa yang mampu dan siap, yakin mampu besaing dalam memasuki dunia kerja.

Kenyataan yang terjadi di lapangan berdasarkan obervasi dan wawancara guru SMK dan siswa SMK (September - Oktober 2018) adanya siswa masih merasa tidak siap untuk memasuki dunia kerja, ada siswa yang menganggap bahwa pelajaran di SMK sulit dan banyak, merasa tidak mampu megerjakan tugas yang diberikan oleh guru mata pelajaran dan pembina organisasi. Selain itu, siswa SMK yang aktif mengikuti kegiatan organisasi merasa kesulitan mengatur waktu sehingga kesulitan dalam menyelesaikan tugas - tugas sekolah yang diberikan. Hal ini, dikarena banyaknya jumlah tugas yang diberikan dan kegiatan-kegiatan organisasi yang harus dipersiapkan, ada juga yang merasa tidak yakin akan kemampuan diri ketika diberikan beban tanggung jawab dalam menjabat suatu jabatan di organisasi. Ada juga siswa SMK merasa tidak yakin mampu untuk memasuki dunia kerja setelah lulus dari SMK, serta ada siswa SMK yang merasa tidak tidak yakin untuk bersaing mengikuti tes seleksi memasuki dunia kerja dengan siswa dari sekolah lainnya. Padahal siswa SMK sudah pernah melakukan praktek atau magang di instasi atau Lembaga pemerintah dan swasta yang disesuaikan dengan jurusan yang mereka pilih.

Permasalahan tersebut mengindikasikan siswa SMK memiliki self efficacy yang rendah. Self efficacy merupakan penilaian terhadap kemampuan diri seseorang, self efficacy merupakan harapan yang dipelajari oleh seseorang bahwa dirinya mampu melakukan suatu perilaku ataupun menghasilkan sesuatu yang di harapkan dalam situasi tertentu (Schunk, dalam Suseno, 2009).

Syarifah Ivonesti, Program Studi Pendidikan Anak Usia Dini STAIN Bengkalis. Email: ivonestis@yahoo.co.id Rany Fitriany, Fakultas Psikologi Universitas Putra Indonesia "YPTK" Padang. Email: ranyfitriany@yahoo.com

Laily Maghviroh, Fakultas Psikologi UIN Sultan Syarif Kasim Riau 
Jurnal Psikologi Malahayati, Volume 2, No.2, September 2020: 48-56

\section{PELATIHAN OUTBOND UNTUK MENINGKATKAN SELF EFFICACY PADA SISWA SMK}

Bandura (Cherian \& Jacob, 2013) berpendapat bahwa self efficacy sebagai sebuah fungsi dari keyakinan diri sendiri yang mana individu dapat menyelesaikan sebuah tugas. Senada, Myers, Vargas-Tonsing, dan Feltz (2005) mengungkapkan self efficacy adalah perasaan yang dimiliki seseorang bahwa dirinya kompeten dan efektif dalam melakukan tugas (Suseno, 2009).

Locke dkk, (Suseno, 2009) mengatakan bahwa self efficacy yang tinggi akan menumbuhkan rasa percaya diri akan kemampuan dirinya dalam melaksanakan tugas. Oleh karena itu penting memiliki self efficacy yang tinggi. Hal ini didukung berdasarkan hasil penelitian yang dilakukan oleh Monika \& Adman (2017) efficacy diri dan motivasi belajar memiliki pengaruh positif terhadap hasil belajar yang dilakukan terhadap 79 siswa SMK swasta di kabupaten Bandung Barat pada program Keahlian Administrasi Perkantoran di kelas XI yang terdiri dari 2 kelas.

Penelitian lainnya oleh Chemers et al. (Monika \& Adman, 2017) bahwa efficacy diri akademik berhububgan dengan prestasi dan penyesuaian diri (secara langsung prestasi akademis, sedangkan secara tidak langsung mempengaruhi melalui harapan dan persepsi terhadap koping).

Bandura (1999) mengatakan bahwa keyakinan akan seluruh kemampuan ini meliputi kepercayaan diri, kemampuan menyesuaikan diri, kapasitas kognitif, kecerdasan dan kapasitas bertindak pada situasi yang penuh dengan tekanan.
Artinya, self efficacy merupakan perasaan untuk mampu, memiliki keyakinan diri yang meliputi kepercayaan diri, kemampuan menyesuaikan diri dengan efektif dan kompeten dalam menyelesaikan tugas-tugas yang diberikan.

Siswa Sekolah Menengah Kejuruan (SMK) harus memiliki self efficacy yang baik. Jika siswa Sekolah Menengah Kejuruan memiliki self efficacy yang tinggi maka siswa Sekolah Menengah Kejuruan akan memiliki rasa percaya diri, memiliki keyakinan diri dalam menghadapi dunia kerja yang akan di jalaninya setelah lulus dari SMK, serta memiliki kemampuan bertindak meskipun dalam keadaan yang tekanan dalam melaksanakan tugas-tugas yang diberikan oleh guru dan yang diberikan pembina organisasi. Dimana setelah lulus dari SMK siswa akan dituntut untuk mampu dan siap bekerja.

Adapun salah satu cara yang dapat dilakukan dalam meningkatkan self efficacy adalah dengan mengikuti pelatihan outbound. Pelatihan outbound diangap relevan oleh peneliti dalam meningkatkan sel efficacy. Hal ini didukung oleh pendapat Ancok (dalam Syafrina, Nashori, \& Rachmahana, 2013) bahwa outbound dapat meningkatkan kemampuan untuk bekerja tim, dapat meningkatkan motivasi dan keyakinan diri akan kemampuan diri serta mampu berpikir kreatif, mampu meningkatkan kebersamaan dan rasa saling percaya dan berupa penyegaran dan memecahkan kekakuan berorganisasi.

Syarifah Ivonesti, Program Studi Pendidikan Anak Usia Dini STAIN Bengkalis. Email: ivonestis@yahoo.co.id Rany Fitriany, Fakultas Psikologi Universitas Putra Indonesia "YPTK" Padang. Email: ranyfitriany@yahoo.com

Laily Maghviroh, Fakultas Psikologi UIN Sultan Syarif Kasim Riau 
Jurnal Psikologi Malahayati, Volume 2, No.2, September 2020: 48-56

\section{PELATIHAN OUTBOND UNTUK MENINGKATKAN SELF EFFICACY PADA SISWA SMK}

Pelatihan yang akan dilakukan adalah dengan metode outbound. Penelitian ini digunakan dengan pelatihan yang memanfaatkan alam (outbound training).

Oleh karena, peneliti menggunakan outbound dimana dengan siswa mengikuti outbound dapat meningkatkan keyakinan diri siswa SMK. Selain itu, outbound merupakan metode yang memberikan stimulasi kehidupan yang kompleks dibuat menjadi sederhana. Metode yang digunakan adalah dengan pendekatan metode belajar melalui pengalaman (experiental learning). Metode outbound di lakukan dengan penuh kegembiraan karena dilakukan dengan permainan Ancok, (Syafrina, Nashori, \& Rachmahana, 2013).

Pelaksanaan pelatihan dengan outbound ini dikembangkan dengan cara belajar dari pengalaman (experiental learning), belajar sebagai kelompok (team learning) dan peningkatan efektifitas tindakan (action learning) (Syafrina, Nashori, \& Rachmahana, 2013). Adapun yang menjadi komponen utama pembelajaran adalah pola perilaku kerja sama, baik yang ditampilkan oleh diri sendiri, maupun oleh sesama peserta latihan. Menurut Ancok (Syafrina, Nashori, Rachmahana, 2013) program permainan outbond berkaitan dengan proses belajar dimana peserta terlibat langsung secara kognitif (pikiran), afektif (emosi), dan psikomotorik.

Penelitian ini bertujuan untuk melihat efek dari pelatihan outbond terhadap efikasi diri siswa
SMK. Adapun hipoesis dalam penelitian ini adalah adanya perubahan self efficacy siswa SMK sebelum dan sesudah diberikan pelatihan outbound.

\section{METODE}

Penelitian ini menggunakan Quasi Experimental, dimana rancangan penelitian berupa one group pretes-post tes design yaitu menggunakan desain kelompok tunggal dengan prates dan pascates yang dilakukan dengan cara memberikan suatu perlakuan pada satu kelompok tampa menggunakan kelompok pembanding (Shaughnessy, Zechmeister, \& Zechmeister, 2000). Penelitian dilakukan terhadap siswa SMK berusia 15 - 17 sebanyak 27 orang siswa SMK.

Intervensi yang diberikan adalah pelatihan outbond yang dilakukan dari pagi sampai sore hari. Adapun tim pemateri atau trainer outbound antara lain Syarifah Ivonesti, M.Psi., Psikolog, Rany Fitriany, M.Psi., Psikolog, Munadi S.Psi. Adapun lokasi intervensi di Bumi Perkemahan UIN Sultan Syarif Khasim. Alat bantu yang digunakan adalah media games permainan - permainan, tenda pleton, lapangan perkemahan, sound system, tape.

Tujuan dari rancangan penelitian ini adalah untuk mengetahui pengaruh suatu perlakukan yang hasilnya diperoleh melalui pengukuran keadaan kelompok sebelum (prates) dan sesudah diberi perlakukan (pascates). Pada awal kegiatan, siswa diberikan skala self efficacy guna mengetahui kondisi

Syarifah Ivonesti, Program Studi Pendidikan Anak Usia Dini STAIN Bengkalis. Email: ivonestis@yahoo.co.id Rany Fitriany, Fakultas Psikologi Universitas Putra Indonesia "YPTK" Padang. Email: ranyfitriany@yahoo.com 
Jurnal Psikologi Malahayati, Volume 2, No.2, September 2020: 48-56

\section{PELATIHAN OUTBOND UNTUK MENINGKATKAN SELF EFFICACY PADA SISWA SMK}

awal subjek. Pasca tes diberikan langsung dengan menggunakan skala self efficacy untuk mengetahui perunbahan yang terjadi terhadap self efficacy siswa SMK.

Penelitian ini tidak menggunakan randomisasi karena terbatasnya jumlah subjek penelitian, dalam hal ini sulitnya memperoleh kelompok kontrol.

Adapun rancangan eksperimen :

$$
\begin{array}{lll}
\mathrm{O}_{1} & \mathrm{X} & \mathrm{O}_{2}
\end{array}
$$

Keterangan :

$$
\begin{aligned}
\mathrm{O}_{1}= & \text { Pemberian skala self efficacy sebelum } \\
& \text { pelatihan } \\
\mathrm{O}_{2}= & \text { Pemberian skala self efficacy setelah } \\
& \text { pelatihan } \\
X= & \text { Intervensi (pelatihan outbound) }
\end{aligned}
$$

Data yang digunakan dalam penelitian adalah skala self efficacy, wawancara dan observasi. Untuk mengukur tingkat self efficacy menggunakan skala self efficacy yang disusun berdasarkan teori Bandura (1986) yang mengungkapkan perbedaan self efficacy pada setiap individu terletak pada tiga komponen yaitu magnitude (tingkat kesulitan tugas), strength (kekuatan keyakinan), dan generality (generalitas). Data tentang self efficacy, dapat diungkap dalam penelitian ini dengan menggunakan instrumen berdasarkan skala likert yang sudah dimodifikasi. Skala dibuat berisi item-item instrumen yang berupa pernyataan dan peskoran menggunakan empat alternatif jawaban untuk setiap pernyataan.
Alternatif jawaban mempunyai empat gradasi yaitu sangat setuju (ss), setuju (s), tidak setuju (ts) dan sangat tidak setuju (sts), dengan jenis item favorable dan unfavorable.

Dalam penelitian ini dilakukan uji validitas yaitu melihat sejauh mana ketepatan dan kecermatan suatu alat ukur dalam melakukan fungsi ukurnya. Berdasarkan hasil uji validitas skala self efficacy sebelum dilakukan outbond dari 41 item diperoleh 12 item yang di nyatakan tidak memuaskan karena nilai validitasnya dibawah 0,30 . Selain itu juga dilakukan uji reliabilitas yaitu melihat derajat ketepatan, ketelitian, atau keakuratan yang ditunjukkan oleh instrumen pengukuran, yaitu sejauh mana suatu alat ukur dapat dipercaya dan diandalkan (Azwar, 2012). Hasil uji reliabilitas pada penelitian ini menggunakan rumus Alpha Cronbach dengan bantuan program IBM SPSS Statistics 22. Koefisien reliabilitas skala self efficacy diperoleh nilai alpha (a) sebesar 0,855. Hal ini menunjukkan bahwa instrumen skala self efficacy yang ada memiliki derajat reliabilitas yang tinggi sehingga memungkinkan atau layak digunakan dalam penelitian.

Data penelitian dianalisis dengan metode kuantitatif. Statistik yang digunakan adalah paired sample t-test. Pairesd t-test digunakan untuk melihat perbedaan sebelum mengikuti pelatihan outbound dan sesudah mengikuti pelatihan outbound. Analisis data ini dilakukan dengan bantuan program komputer SPSS for Ms windows release 16.

Syarifah Ivonesti, Program Studi Pendidikan Anak Usia Dini STAIN Bengkalis. Email: ivonestis@yahoo.co.id Rany Fitriany, Fakultas Psikologi Universitas Putra Indonesia "YPTK" Padang. Email: ranyfitriany@yahoo.com 


\section{PELATIHAN OUTBOND UNTUK MENINGKATKAN SELF EFFICACY PADA SISWA SMK}

Analisis kualitatif dilakukan berdasarkan hasil observasi, wawancara dan perilaku siswa SMK serta hasil dari lembar tugas (work sheet) yang diberikan selama proses penelitian berlangsung. Wawancara di lakukan pada saat siswa setelah pelatihan berkangsung di sekolah. Metode ini dilakukan untuk memperoleh data kualitatif berupa kondisi subjek berupa pengaruh pikiran, perasaan dan pengaruh yang dirasakan setelah mengikuti pelatihan. Observasi di lakukan pada saat pelatihan berlangsung. Proses obeservasi dilakukan dengan pencatatan langsung berupa lembar cheklis dan diberikan penjelasan secara kualitatif mengenai keaktifan subjek, sikap dan lain-lain. Lembar tugas yang terdiri dari beberapa pertanyaan yang harus di jawab secara tertulis oleh subjek sehingga subjek menjadi insigt dengan kondisi yang dialami keterkaitan dengan materi yang disampaikan di dalam pelatihan.

HASIL

Berdasarkan data pretes dan posttes skala self efficacy diketahui $\mathrm{t}(27)=2.075, \mathrm{p}<.05$ berarti hipotesis diterima yaitu ada perbedaan self efficacy sebelum pelatihan outbond (pretes) dan setelah mengkuti pelatihan outbound pada siswa SMK (postes). Mean dari skala self efficacy pada data prates dan postes adalah sebesar 5.893 dengan standar deviasi sebesar 15.024 .

Adapun perbandingan rata-rata skor skala self efficacy pada saat pretes dan postes dapat dilihat bahwa rata-rata sebelum diberikan outbond adalah 125.79 dan setelah diberikan outbond sebesar 125.93 seperti yang terdapat pada gambar dibawah ini :

\section{Gambar 1}

\section{Perbandingan Rata-rata Skor Skala Self Efficacy Prates dan Paskates}

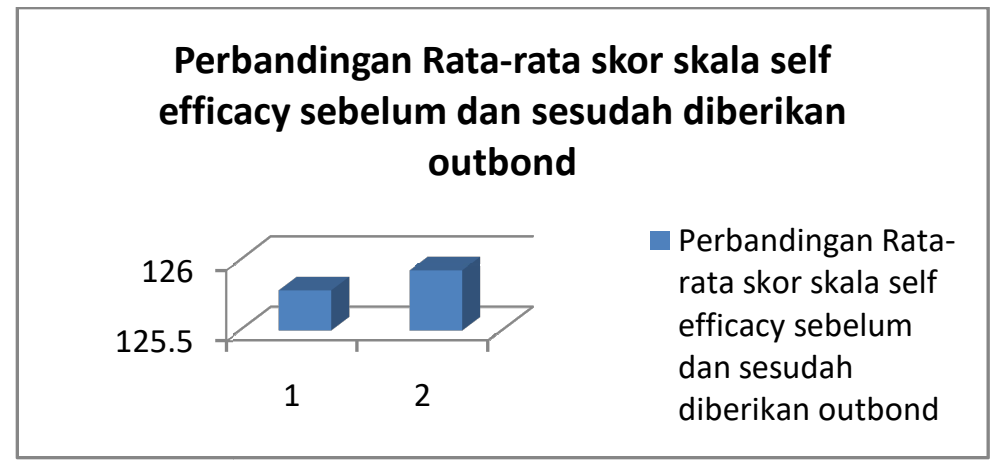

Syarifah Ivonesti, Program Studi Pendidikan Anak Usia Dini STAIN Bengkalis. Email: ivonestis@yahoo.co.id Rany Fitriany, Fakultas Psikologi Universitas Putra Indonesia "YPTK" Padang. Email: ranyfitriany@yahoo.com 
Jurnal Psikologi Malahayati, Volume 2, No.2, September 2020: 48-56

\section{PELATIHAN OUTBOND UNTUK MENINGKATKAN SELF EFFICACY PADA SISWA SMK}

\section{DISKUSI}

Pelatihan outbound yang diberikan dalam penelitian ini bertujuan untuk meningkatkan self efficacy siswa SMK. Berdasarkan analisis data prates dan pasca tes yang menggunakan paired sample ttest, diketahui ada perbedaan antara data prates dan pasca tes skala self efficacy. Hal tersebut menunjukkan kondisi yang berbeda yaitu menggambarkan sebuah situasi yang terjadi dimana siswa SMK memiliki self efficacy yang meningkat setelah mengikuti pelatihan outbound. Hal ini, didukung Ancok (Syafrina, Nashori, \& Rachmahana, 2013) adapun tujuan outbound yaitu meningkatkan kemampuan pegawai untuk berkerja dalan tim, meningkatkan motivasi dan keyakinan diri peserta akan kemampuan diri (personal development) serta mampu berpikir kreatif (inovasi), meningkatkan kebersamaan dan rasa saling percaya (trust), penyegaran dan memecahkan kekakuan birokrasi. Keyakinan diri atau self efficacy peserta di dalam penelitian ini menjadi meningkat.

Menurut Astuti (Harsanti, 2018) pelatihan ini menggunakan metode experience learning (belajar melalui pengalaman langsung) yang disajikan dalam bentuk permainan, simulasi, diskusi dan petualangan sebagai media penyampaian materi. Peserta pelatihan outbound di setiap sesi pelatihan outbound di berikan games atau permainan yang disesuaikan berdasarkan sistuasi keseharian di dalam bentuk games. Artinya dalam pelatihan outbound ini siswa secara aktif dilibatkan dalam seluruh kegiatan yang dilakukan dengan terlibat secara aktif. Siswa terlibat pada aktivitas (learning by doing) langsung mendapatkan umpan balik tentang setiap aktivitas yang dilakukan sehingga langsung mendapatkan dampak sebagai pengembangan diri untuk menjadi lebih baik.

Hal lainnya, yang mendukung pelatihan outbound ini antara lain menayangkan filim yang kondisi sesuai dengan peserta pelatihan dalam meraih cita-cita, film ini ditampilkan melalui infokus di dalam tenda pelatihan. Selain itu, peserta diberikan lembar tugas untuk dituliskan dari lembar tugas yang digunakan untuk langsung menerapkan atau mempraktekan materi yang diberikan di dalam suatu permainan atau games. Serta di setiap games yang telah dilakukan peserta langsung diberikan umpan balik oleh trainer. Dengan adanya proses belajar yang efektif dari peserta melalui simulasi - simulasi permainan dan proses debrief agar mendapatkan insight makan dapat memberikan manfaat kepada peserta.

Ancok (Syafrina, Nashori, \& Rachmahana, 2013) pelatihan outbound ini dapat meningkatkan kemampuan pegawai untuk bekerja, bekerja dalam tim, dapat meningkatkan motivasi dan keyakinan diri akan kemampuan serta mampu berpikir kreatif, mampu meningkatkan kebersamaan dan rasa saling percaya, dan berupa penyegaran dan memecahkan kekakuan organisasi.

Syarifah Ivonesti, Program Studi Pendidikan Anak Usia Dini STAIN Bengkalis. Email: ivonestis@yahoo.co.id Rany Fitriany, Fakultas Psikologi Universitas Putra Indonesia "YPTK" Padang. Email: ranyfitriany@yahoo.com

Laily Maghviroh, Fakultas Psikologi UIN Sultan Syarif Kasim Riau 
Jurnal Psikologi Malahayati, Volume 2, No.2, September 2020: 48-56

\section{PELATIHAN OUTBOND UNTUK MENINGKATKAN SELF EFFICACY PADA SISWA SMK}

Selanjutnya, secara umum proses pembelajaran yang terjadi dalam pelatihan outbooud dipengaruhi oleh karakteristik peserta pelatihan, karakteristik desain penelitian (Goldstein \& Ford, 2002). Desain pelatihan terdiri atas tujuan pelatihan yang akan memengaruhi bagaimana prosedur pelatihan yang disusun dan pemilihan metode yang digunakan. Karakteristik peserta pelatihan yang mempengaruhi adalah kesiapan peserta untuk belajar dan juga motivasi untuk belajar dan mengikuti pelatihan. Kemudian terdapat juga aspek suasana pelatihan berlangsung.

\section{SIMPULAN DAN SARAN}

Berdasarkan hasil penelitian yang dilakukan, maka dapat disimpulkan pelatihan outbound merupakan solusi pemecahan masalah pada self efficacy siswa Sekolah Menengah Kejuruan. Pelatihan outbound memiliki dampak positif terhadap siswa, maka diharapkan outbound dikembangan di SMK khususnya di tempat penelitian dan dijadikan program kegiatan tambahan di sekolah - sekolah kejuruan. Diharapkan kepada subjek pelatihan untuk menerapkan materi-materi yang disampaikan dalan kehidupan sehari-hari agar menjadi pembiasaan.

\section{DAFTAR PUSTAKA}

Azwar, S. (2012). Penyusunan skala psikologi edisi II. Yogyakarta: Pustaka Pelajar.
Bandura, A., Freeman, W. H., \& Lightsey, R. (1999). Self-efficacy: The exercise of control.

Cherian, J., \& Jacob, J. (2013). Impact of self efficacy on motivation and performance of employees.

Departemen Pendidikan dan Kebudayaan (2004). GBPP. Kurikulum SMK 2004. Jakarta: Dept P $\& \mathrm{~K}$.

Depdiknas, (2006). Peraturan Menteri Pendidikan Nasional Republik Indonesi Nomor 23 Tahun 2006 Tentang Standar Kompetensi Lulusan Umtuk Pendidikan Dasar dan Menengah. di akses $\quad 10 \quad$ Agustus 2020 (http://akhmadsudrajat.file.wordpress.com)

Goldstein, I. L., \& Ford, J. K. (2002). Training in organization: Needs assessment, development and evaluation, CA: Wadsworth Group, Thompson Learning.

Harsanti, A. G. (2018). Pengembangan Perangkat Pembelajaran dengan Menggunakan Outbond untuk Peningkatan Perilaku Sosial Siswa Kelas IV SDN 01 Tawangrejo. Buana Pendidikan: Jurnal Fakultas Keguruan dan IImu Pendidikan, 14(25), 21-29.

Monika, M., \& Adman, A. (2017). Peran efikasi diri dan motivasi belajar dalam meningkatkan hasil belajar siswa sekolah menengah kejuruan. Jurnal Pendidikan Manajemen Perkantoran (JPManper), 2(2), 219-226.

Syafrina, R., Nashori, F., \& Rachmahana, R. S. (2013). Pengaruh Pelatihan Outbond terhadap Peningkatan Tim Kerja Guru Madrasah Tsanawiyah â€ œJbâ€. JIP (Jurnal Intervensi Psikologi), 5(1), 43-58.

Shaughnessy, J. J., Zechmeister, E. B., \& Zechmeister, J. S. (2000). Research methods in psychology. McGraw-Hill.

Syarifah Ivonesti, Program Studi Pendidikan Anak Usia Dini STAIN Bengkalis. Email: ivonestis@yahoo.co.id Rany Fitriany, Fakultas Psikologi Universitas Putra Indonesia "YPTK" Padang. Email: ranyfitriany@yahoo.com 
Jurnal Psikologi Malahayati, Volume 2, No.2, September 2020: 48-56

PELATIHAN OUTBOND UNTUK MENINGKATKAN SELF EFFICACY PADA SISWA SMK

Suseno, M. N. M. (2009). Pengaruh pelatihan komunikasi interpersonal terhadap efikasi diri sebagai pelatih pada mahasiswa. JIP (Jurnal Intervensi Psikologi), 1(1), 93-106.

Widyasari, A. (2015). Pengembangan Modul Fisika Kontekstual pada Materi Usaha, Energi, dan Daya untuk Peserta Didik Kelas X SMK Harapan Kartasura (Doctoral dissertation, UNS (Sebelas Maret University)).

Myers, N. D., Vargas-Tonsing, T. M., \& Feltz, D. L. (2005). Coaching efficacy in intercollegiate coaches: Sources, coaching behavior, and team variables. Psychology of Sport and Exercise, 6(1), 129-143.

Bandura, A. (1986). The explanatory and predictive scope of self-efficacy theory. Journal of social and clinical psychology, 4(3), 359-373.

Syarifah Ivonesti, Program Studi Pendidikan Anak Usia Dini STAIN Bengkalis. Email: ivonestis@yahoo.co.id Rany Fitriany, Fakultas Psikologi Universitas Putra Indonesia "YPTK" Padang. Email: ranyfitriany@yahoo.com 